\title{
AN ANALYISS OF PRE - SERVICE TEACHER EDUCATION FOR INCLUSION OF CHILDREN WITH HEARING IMPAIRMENT
}

\author{
Stackus Okwaput \\ Faculty of Special Needs and Rehabilitation, Kyambogo University
}

\begin{abstract}
Proponents of inclusion in special needs education argue that it is a human right for children with special needs to attain education with their ordinary peers. Underlying inclusion is the assumption thast teachers have the knowledge for addressing the diverse needs of learners in their classrooms. This study explored the provisions that might enable pre-service teacher trainees in Uganda to acquire knowledge for implementing inclusion for children with hearing impairment and the challenges that may hinder them from achieving that goal. The sample consisted of five teacher trainers and six teacher trainees. Data was collected using focus group discussions and interviews and analyzed following the thematic analysis procedures. The findings show that trainees might acquire knowledge for implementing inclusion from provisions made in the syllabus for special needs education and the college. Challenges in the teacher education system and negative attitudes may, however, hinder the achievement of this goal.
\end{abstract}

Keywords: Teacher Education, Inclusion, Qualitative Approach

\section{Introduction}

There is an increase in advocacy for the policy and practice of inclusion world-wide. This development is largely attributed to the declarations made during the Salamanca Conference on special needs education (UNESCO 1994). Inclusion is hitherto considered to be human-rights based approach to education that is aimed at enabling children with special needs to attain education alongside their peers (Watkins and Donnelly 2014). In Uganda, inclusion was adopted in 1997 following the introduction of universal primary school education (UPE) policy. The policy is implemented in a way that Government provides free education for four children in each family, and priority is given to children with disabilities. The UPE policy, therefore, led to an increase in the number of children with children with disabilities who are enrolled in ordinary schools. In order to meet the demand for teachers who implement inclusion, a training course unit aimed at enabling pre service teacher trainees to develop knowledge

* Corresponding author: Stackus Okwaput

stackuso@gmail.com

Published online at http://IJDS.ub.ac.id/

Copyright @ 2018PSLD UB Publishing. All Rights Reserved and skills in special needs education and inclusion was started in 1997.

\subsection{Problem statement}

The Uganda Statistical Abstract, 2015, shows that children with hearing impairment constitute the largest number $(29 \%)$ of the children with disabilities who have been enrolled in schools (Uganda Bureau of Statistics 2015). These children are expected to benefit from the current policy on inclusion. Owing to the hearing loss, however, these children may experience challenges that may hinder successful inclusion in classrooms which they are placed. Barnet (2002); Girgin (2007); Cole and Flexer (2007) report that children with hearing impairment experience perceptional difficulties which may affect their participation in ordinary classroom activities. A similar observation is made by Silvestre, Ramsport and Pareto (2006) noting that the communication difficulties associated with hearing loss may make children with hearing impairment vulnerable to developing low self esteem and social and emotional problems compared to their hearing peers. Kluwin, Stinson and Colarrosi (2002) cited in Wauters and Knoors (2007) also observe that children who are deaf 
may experience less interaction with peers, have fewer friends and are more often rejected. This observation is consistent with Lucas et al. (2008) who observe that social and emotional problems among children with hearing impairment may arise partly due to peer ostracism and the hearing impaired child's unfamiliarity with the larger culture of peers who do not have hearing difficulties.

The above observations imply that in order to implement inclusion in classrooms which have children with hearing impairment, teachers should be equipped with knowledge that can enable them to meet the needs of the children in those settings. Teachers determine what happens in the classroom and one would argue that the success of inclusion in classrooms which have children with hearing impairment requires teachers who are knowledgeable and can ably make modifications in the environment and the curriculum in order to enhance participation of these children. The importance of preparing teachers for inclusion is also underscored by the observation that inadequate training in special needs education is one of the major difficulties met by teachers in their efforts to support children with special needs (Arbeiter and Hartley 2002; Olivia and Williams 2005). A body of literature also indicates that some teachers express concerns about their lack of preparation for inclusion and for teaching all learners (Forlin 2001) and that appropriate training of teachers is crucial if they have to be confident and competent in teaching children with special needs (World Health Organization, 2011).

Some authors have considered the modalities for training teachers for special needs education and inclusion. Brown et al. (2008) found out that embedding special needs education instruction into a pre-service general education course significantly increased teacher candidates' knowledge of inclusion and their confidence levels. Teacher training for inclusion can also be implemented as an elective course unit, a compulsory course unit or a separate specialized training programme. Literature about the impact of using any of these modes in training teachers for inclusion of children with hearing impairment is still scarce. A study by Stella, Forlin and Lan (2007) cited by Woodcock (2013), however, indicate that trainees who took special needs education as a compulsory course unit expressed more discomfort than those who took it as an elective. Acedo et al. (2009) observe that due to a variety of challenges that teachers are confronted with in schools, separate pre-service teacher education training programmes may not be useful because specialization may limit the range of pupils that teachers who are trained in a specialized setting can teach. This view is consistent with Florian and Rouse (2009) observation that elective modules or course units for special needs education in initial teacher education serve to reinforce the sense that children with special needs are a responsibility of only those who have undertaken the specialist courses.

The teaching methods that are considered to be effective in preparing teacher trainees for inclusion have also been considered some authors. For instance, The European Agency for Development in Special Needs Education (2010) advocates for use of reflective teaching approach. The Agency observes that this approach may enable teacher trainees to reflect on their role of meeting the varying needs of children with special needs in relation to their own context. If this view is agreed with, it implies that teacher education for inclusion of children with hearing impairment should provide opportunity for trainees to reflect on the context of their schools, classrooms and communities. Korthagen et al. (2006), however, argues that exhorting teacher trainees to be reflective practitioners does not necessarily make them change what happens in schools. Korthagen et.al (2006) view suggests that there are other factors which should be addressed in order for successful inclusion to happen. Some authors such as Bronack et al. (2006); Alvesson and Skoldberg (2009), however, advocate for teaching methods that are based on the social constructivist perspective to learning. In this perspective, learning is not something naturally given but is constructed through interaction with other people and the environment. Teaching methods that are based on this perspective may, therefore, be useful in teacher education special needs education and inclusion because they provide opportunity for the learners to participate in creating knowledge.

Regarding the subject content necessary for trainees to acquire knowledge for implementing inclusion, Kershner (2008) observes that teachers' knowledge for meeting the needs of children with special needs can be extended by guiding them to understand child 
development in context. Kershner (2008) view implies that in order to be able to implement inclusion in classrooms which have children with hearing impairment, teacher trainees should learn about child development in relation to these children. Casey and Childs (2007); Wormnæs (2008) and World Health Organization (2011) also observe that appropriate training of teachers should not focus on knowledge and skills only, but also on addressing attitudes and values of trainees. They note that the values that teacher trainees hold form the foundation for developing knowledge necessary for working in inclusive classrooms. This assertion aligns with Boling (2007) view that teacher educators should influence trainees to challenge prior assumptions and beliefs as a requisite for them to implement inclusion. John and Fuller (2013), however, indicate that even when training is provided, some trainees still leave initial teacher education without the knowledge needed to work with future children with special needs. The above observations imply that there are factors that ought to be addressed in order for teacher education for inclusion to achieve the goal of empowering trainees and to develop knowledge for implementing this provision.

The study reported in this paper explored the provisions that might enable pre - service teacher trainees in Uganda to acquire knowledge for implementing inclusion in classrooms which have children with hearing impairment and the challenges that may hinder them from achieving that goal. Literature about how teacher education prepares trainees in the above aspect is scarce, and no study has been conducted regarding this phenomenon in Uganda. The findings from this study may, therefore, contribute to bridging the existing gap.

\section{Research Design}

A qualitative approach was followed in this study. In choosing this approach, I was inspired by the assertion that descriptive information from qualitative studies may lead to a better understanding of individuals with special needs, their families and those who work with them (Blantilinger et al, 2005). Furthermore, the assumption that issues such as the vivid personal feelings and opinions of the informants are appropriately elicited using a qualitative research approach rather than the quantitative approach influenced my choice for the approach.

\subsection{Informants}

The study was conducted in five pubic teacher education colleges which implement pre-service teacher education in special needs education, a course unit within which aspects about inclusion are expected to be taught. Although there are 45 colleges in this category, the five colleges were purposively selected on the basis that they were known to have teacher trainers who are trained in special needs education. The informants were: Five teacher trainers for special needs education one from each of the five colleges involved in the study and six first-year teacher trainees from one college. Teacher trainers for special needs education were selected because they are responsible for preparing trainees for inclusion. First-year teacher trainees were selected because a large portion of the subject content in the syllabus is expected to be covered in the first year of study.

\subsection{Methods}

Three methods were used for data collection and these are; document study, individual interviews and focus group discussions. The decision to use document study was based on the intention to explore the provisions that have been made in the teacher education documents and how they are implemented in order to enable trainees to develop knowledge for implementing inclusion in classrooms which have children with hearing impairment. Individual interviews were selected basing on the assumption that this method of data collection provides an opportunity for a dialogue which may influence the interviewee to describe his/her ideas and feelings about a phenomenon in-depth (Kvale 1996). Focus group discussion method was selected basing on the view that the interaction that takes place during the discussion may stimulate individuals to express their feelings and perceptions about a phenomenon (Marshall and Rossman 1994).

\subsection{Procedure for Data Collection}

The study started with a review of five documents used in teacher education. The documents were reviewed to obtain information regarding the subject content provided, time allocation, materials used and teaching methods. After reviewing the documents, five 
open ended individual interviews were conducted with teacher trainers for special needs education. The dates and time for interviews were agreed upon but at the convenience of the informants. After the interviews, five focus group discussions were held with a group of six teacher trainees. The focus group discussions were held after the trainees had undergone their first school attachment. Holding the discussions after the attachment provided an opportunity for exploring trainees' experiences regarding how they might have been supported to develop knowledge for implementing inclusion in classrooms which have children with hearing impairment.

\subsection{Data Analysis}

Thematic data analysis procedure was followed as guided by Miles and Huberman (1984), Braun and Clarke (2006) and Boeije (2010). The process involved transcribing field notes with detail that is sufficient to give meaning, identifying significant statements/issues, categorizing them and presenting them in contact summary forms adapted from Miles and Huberman (1984). The categorized statements/issues were then cut into pieces and clustered into themes in which the findings are presented.

\subsection{Ethical Considerations}

Permission to conduct the study was sought from the Ministry of Education and Sports (MOES). Furthermore, the informants where requested to participate in the study in writing, and were informed of their right to withdraw if they so wished. Informants were given assurance that all information provided would be kept anonymous.

\subsection{Validity and Reliability}

Two procedures where employed in an attempt to enhance validity and reliability in the study: First, data was collected using three research methods; document studies, interviews and focus group discussions. Use of three research methods provided an opportunity for corroborating the data obtained. Secondly, the study involved two categories of informants; teacher trainers for special need education and teacher trainees. These categories of informants were expected to have varying experiences about the phenomenon under study. This enabled the author to check the plausibility of the data obtained.

\section{Results}

The findings are presented in two themes; Provisions that might enable trainees to acquire knowledge for implementing inclusion and the challenges that might hinder them from achieving that goal.

\subsection{Provisions that might enable trainees acquire knowledge for implementing inclusion in classrooms which have children with hearing impairment}

The data shows that there are two main categories of provisions that might enable teacher trainees to acquire knowledge for implementing inclusion and these are; resources for teacher education and the policy provisions.

\subsubsection{Resources for teacher education}

The syllabus for special needs education All the colleges involved in the study have the syllabus for training teachers in special needs education. The syllabus presents outlines of topics, subject content, teaching materials and learning outcomes for each of the topics that is expected to be taught with regard to the various categories of children with special needs. All the teacher trainers who participated in the study revealed that they follow the syllabus as a guide for preparing trainees. The syllabus provides that special needs education is a compulsory course. The teacher trainers are expected to interpret the outlines in the syllabus and use it to develop more detailed plans for supporting trainees to develop knowledge in various aspects of special needs education including learning about inclusion. The data, however, shows that the syllabus is lacking in terms of what the trainers need in order to be able to prepare the trainees for the role expected of them. When asked about the availability of the syllabus, one teacher trainer said "there is a syllabus, it is not detailed and it calls for more research". Another said "the syllabus just gives a general view of what should be taught...I use the background knowledge that I acquired during the training". The above responses suggest that although the special needs education course may be implemented in all the colleges, the subject content offered may not be sufficient and might vary significantly from one 
college to another depending on how the teacher trainers interpret the syllabus.

The syllabus has a topic titled "teaching children with hearing impairment" and is allocated only five hours. However, when asked what they had learnt about hearing impairment, one teacher trainee said "We haven't learnt much. We have only learnt a basic tip about how to communicate in sign language". Given that children with hearing impairment may be hard of hearing or deaf, the five hours allocated for the above subject content may not be sufficient for trainees to acquire knowledge that is sufficient for implementing inclusion in classrooms which have these children.

The course outline in the section for hearing impairment shows that trainees are expected to learn what it is, its causes, how to identify persons with that condition, teaching children with hearing impairment, improving their social skills and how to use sign language to teach them. This subject content, although necessary, may not be sufficient to enable trainees implement inclusion for this category of children. Furthermore, there was no subject content about implementing inclusion in classrooms which have children with hearing impairment. One teacher corroborated this observation saying that "we give them elementary information, mostly how to assess learners with hearing impairment...that is what the curriculum [syllabus] dictates."

The syllabus also has a topic which provides opportunity for trainees to learn about addressing negative attitudes towards children with disabilities. It states that "students should develop positive attitudes towards teaching children with special needs and to identify strategies on how to eradicate those attitudes".

The data also shows that the syllabus provides opportunity for trainees to experience teaching methods that they might use when implementing inclusion in classrooms which have children with hearing impairment. The teacher trainers revealed that they use participatory methods of teaching. When asked what methods she uses, one teacher trainer said " I use my own methods, sometimes I use storytelling, dramatization and group work", another said " for me in most cases, I use practical methods in a situation where I am teaching them to teach learners with hearing impairment". Knowledge about these methods might enable trainees to support children with hearing impairment and their peers to be acquainted with each other and to participate in learning activities in inclusive classrooms. The data did not, however, show that the teacher trainers use reflective teaching approaches in the training. Teacher educators who have training in special needs and inclusive education .

All the colleges in which the study was conducted have teacher educators who have undergone at least a two -year general training in special needs and inclusive education. This provision may enable the teacher educators to support trainees to develop knowledge for implementing inclusion in classrooms which have children with hearing impairment. Some of the teacher trainers, however, did not take the course on hearing impairment as their area of specialization. One teacher trainer said "I didn't specialize even at Bachelors level, so there are areas [of special needs education] which I cannot excel in". This indicates that in spite of the general training that they have in special needs and inclusive education, some teacher trainers may not be knowledgeable about how to address the learning needs of children with hearing impairment in inclusive classrooms. This implies that they might not have the competency to support the trainees to acquire knowledge in that aspect. The data also shows that each of the colleges has only one teacher educator for special needs and inclusive education. The one teacher educator may be overloaded and, hence, may not be able to support the large number of trainees in the colleges.

\subsubsection{Policy provisions}

The data shows that teacher education for special needs and inclusive education is a compulsory course unit that is undertaken over the period of two years. Given that inclusion is one of topics that may be covered in the course, this policy may implore trainees to develop knowledge for implementing inclusion in classrooms in which children with hearing impairment are enrolled.

Another finding is that the colleges are expected to provide equal opportunity for applicants with hearing impairment to enroll as trainees. All the teacher trainers reported that the colleges accept trainees with hearing impairment if they meet the entry requirements. At the time of the study, one of the colleges had enrolled a trainee with hearing impairment. This policy provides opportunity for trainees 
with hearing impairment to share experiences with their peers, a factor that might enhance their knowledge. The data, however, shows that some of the teacher trainers have negative opinions about the enrolment of trainees with hearing impairment for the teacher education course. One teacher trainer said "there should be a college which is in charge of training trainees with hearing impairment... those students do not benefit in some disciplines here in the college". Such opinion might have a negative influence on the trainers ability to support trainees to develop knowledge for implementing inclusion in classrooms which have children with hearing impairment.

\subsection{Challenges that may hinder trainees from developing knowledge for implementing inclusion in classrooms that have children with hearing impairment}

\subsubsection{Challenges pertaining to the teacher education system}

In Uganda, teacher education for special needs education and inclusion is not implemented as course on its own but is a course unit under the Professional Education Studies Course. The data indicates that this arrangement might influence trainees to have a low perception about the course unit because of the small contribution that it makes towards their final grade. One teacher trainer said "hiding of special needs education to be just a unit under professional education studies...it is challenging and unfair and even the students take it lightly, you end up getting some dodging [classes]". This arrangement might not motivate trainees to acquire knowledge that would enable them to implement inclusion.

Another challenge is that the syllabus does not provide in-depth subject content about hearing impairment and inclusion. For instance, there is no subject content about how inclusion can be implemented in classrooms which have children with hearing impairment. The exclusion of such vital subject content might not enable teacher trainees to acquire knowledge in that aspect. One teacher trainers stated; "they just give definitions and what entails inclusion of children with hearing impairment is missing" and another said "we give some elementary information... I cannot now teach how to teach learners with hearing impairment in details"
The data also shows that special needs education is allocated only two hours a week and 55 hours in total for the two year teacher education programme. One teacher trainer said; "the time is not enough and the content provided [for special needs education] is very shallow". This time schedule is not sufficient for the teacher trainers to support trainees in the various areas of subject content related to addressing the diverse needs of children with hearing impairment.

\subsubsection{Challenges pertaining to the colleges}

The data shows that some teacher trainers did not have sufficient knowledge about inclusion and how it can be implemented. When asked how the syllabus can be improved, one teacher trainer said; "principles of inclusion and benefits so that the trainees go knowing how important it is". Learning about principles of inclusion and its benefits, although important, is not sufficient to enable a teacher to implement inclusion in classrooms that have children with hearing impairment.

The other challenge pertains to access to literature. All the teacher trainers who participated in the study revealed that their colleges did not have reference materials for special needs and inclusive education in general and hearing impairment in particular. One teacher trainers said "there are no reference materials, it is the initiative of the tutor who handles the course to look for the materials" and another said "actually it [reference books] is not there, what I have here for students are only the sign language manuals".

\section{Discussion}

The global agenda of inclusion as agreed during the Salamanca Conference (UNESCO 1994) necessitates that steps should be taken to explore how this 'new' provision can be implemented in light of the varying national contexts. Among the aspects that should be considered in this process is how teacher education should prepare pre-service teacher trainees in order to develop their knowledge for meeting diversity in inclusive classrooms.

The data shows that teacher education about inclusion is part of what is covered in the course unit for special needs education. Trainees are expected to acquire knowledge for implementing inclusion in classrooms which have children with hearing impairment through the subject content that is provided in the 
syllabus. Embedding inclusion education in the special needs education course unit which is part of the general teacher education course might enable trainees to appreciate inclusion as a provision which is a right for all learners. This aligns with Brown et al. (2008) observation that embedding special needs education instruction into a pre-service course significantly increased trainees' knowledge about inclusion. The data, however, indicates that the subject content is in adequate and, hence, might not enable trainees acquire knowledge for implementing in classrooms that have children with hearing impairment. Girgin (2007); Cole and Flexer (2007) observe that that category of children experience a range of difficulties which may hinder their participation in learning. This implies that in order to implement inclusion in classrooms that have children with hearing impairment, teachers should have in-depth knowledge on how to address the varying needs of learners in such classrooms.

The data further shows that the special needs education course is compulsory for all trainees. Some trainees, however, revealed that they had not learnt much regarding children with hearing impairment and inclusion. This could be attributed to the insufficient subject content about hearing impairment and inadequate time provided for it. Hearing impairment is a broad area which ought to be considered in its entirety. Deng (2004) argues that initiating teachers into wider contexts of theory about worthwhile perspectives and understanding is desirable if they are to learn to teach in new ways and become well informed and morally sensitive professionals. This finding lends credence to Forlin and Lan (2007) cited by Woodcock (2011) observation that trainees who took the special needs education as a compulsory course expressed more discomfort that those who took it as an elective.

The colleges had teacher educators who are trained in special needs education. The trainers have a key role to influence trainees to appreciate their future professional responsibility of ensuring the provision of education for all (Boling 2007; Wormnæs 2008). The data, however, shows that some of the teacher trainers did not have training in the area of hearing impairment. In addition, some teacher trainers also have negative perceptions about the enrolment of trainees with hearing impairment in teacher education colleges.
Personal experiences and positive attitudes of the teacher shape the way they see their professional future. Negative perceptions and lack of knowledge about hearing impairment may, therefore, negatively impact on the teacher trainers' ability to support trainees to develop knowledge for implementing inclusion in classrooms which have children with hearing impairment.

It is worth noting that Government of Uganda has some policies and legislation which are aligned towards inclusion of children with hearing impairment. Government also ratified the Convention on the Rights of Persons with Disabilities (CRPD) and pledged to address the concluding observations and recommendations made by the Committee on the CRPD in 2016. To this end, therefore, government of Uganda has the responsibility to ensure that teacher education prepares new teachers in a way that might enable them to develop competencies for meeting the diverse needs of learners in their future classrooms. A crucial element in the development of inclusive practices is better preparation of and support for teachers that equips them with knowledge about what they are expected to do and molding them to develop a positive attitude towards all learners. With regard to inclusion in classrooms which have children with hearing impairment, the findings indicate that there is a gap between existing policy framework and the practice of teacher education for special needs education and inclusion. The way forward, therefore, is to address this gap.

\section{Limitations}

The author acknowledges that the study has some limitations: First, although it was useful to collect data from several teacher trainers for special needs education, only five trainers could be selected to participate in the study, a number which is small. This implies that there was limited access to a variety of data that would permit a more rigorous analysis. Second, this study may be one of the very few studies that attempt to investigate how teacher trainees are prepared in order to develop their knowledge for implementing inclusion in classrooms which have children with hearing impairment. Literature about this phenomenon was scarce. This may have negatively influenced the development of tools and interpretation of findings. Third, this study considered data which was obtained from trainees who were 
enrolled in the first year of the teacher education programme. At the time of study, this group of trainees had been in the college for less than one year. Perhaps the findings would have been different if data was collected from year two trainees too. The assumption is that trainees who are in the second year may have more experiences regarding the training compared to their peers who are in first year.

\section{Recommendations}

The findings point to the need to reconsider pre-service teacher education for inclusion with a focus on supporting trainees to develop theoretical knowledge about inclusion, children with hearing impairment and strategies for ensuring participation of this category of children in inclusive classrooms. Three aspects, therefore, seem to be desirable in achieving this direction; first, teacher trainers ought to be retrained to enable them acquire the competencies necessary for supporting trainees in that aspect. Secondly, subject content in the syllabus for special needs education should be enhanced in light of what is needed to make a teacher who can effectively implement inclusion in classrooms which have children with hearing impairment. Third, in order to motivate trainees, the special needs education course unit should be upgraded to a stand-alone course and the number of hours increased commensurate to the subject content. The findings provide a framework for future investigations on how teacher trainees are being prepared for implementing inclusion of children with hearing impairment.

\section{References}

UNESCO. (1994). The Salamanca Statement and Framework for Action on Special Needs Education. Paris: UNESCO

Watkins A, Donnelly V. Core Values as a Basis for Teacher Education for Inclusion. Global Education Review. 20014; 1 (1): 76-92.

Uganda Bureau of Statistics. (2015). The Statistical Abstract, 2015. Kampala: UBOS

Barnett, S. (2002). Communication with deaf and hard-of-hearing people: a guide for medical Education. Academic Medicine. 2002; 77(7): 694-700.
Girgin M C. (2007). Speaking rates of Turkish prelingually hearing-impaired children. A Paper presented at the International Educational Technology (IETC) Conference, Nicosia ; May 3-5, 2007.

Cole E B, Flexer C. (2007). Children with Hearing Loss: Developing Listening and Talking. San Diego, CA: Plural

Silvestre N, Ramspott A, Pareto I. (2006). Conversational skills in a semi structured interview and self concept in deaf students. Journal of Deaf Studies and Deaf Education. 2006; 12(1): 38-54.

[8.] Wauters L N, Knoors H. (2007) Social integration of deaf children in inclusive settings. Journal of Deaf Studies and Deaf Education. 2007; 13(1): 21-36.

Lucas T, Villegas A M, Freedson-Gonzalez M. (2008). Linguistically responsive teacher education: preparing classroom teachers to teach English language learners. Journal of Teacher Education. 2008; 59(4); 361-373

Arbeiter S. Hartley S. (2002). Teachers' and pupils' experiences of integrated education in Uganda. International Journal of Disability, Development and Education. 2002; 49(1): 6178.

Oliver M, Williams M. (2005). Teaching the mentally handicapped child: challenges teachers are facing. International Journal of Special Education. 2005; 20(2): 19-31.

Forlin C. (2000). Inclusion: Identifying potential stressors for regular class teachers. Educational Research. 200; 43 (3): 235-245

World Health Organization. (2011). World Report on Disability. Geneva, WHO

Brown K S, Welsh L A, Hill K H, Cipko J P. (2008). The efficacy of embedding special education instruction in teacher preparation programmes in the United States. Teaching and Teacher Education. 2008; 24(8): 2087-2094

Woodcock S, (2013). Trainee Teachers' Attitudes Towards Students with Specific Learning Disabilities. Australian Journal of Teacher Education. 2013; Vol .38 (8): 16-29

Acedo C, Amadiao M, Oppperti R, Brady J, Duncombe L, Weyermann M, Xu X (Eds.). (2009). Defining an Inclusive Education Agenda: Reflections Around the 48th Session 
of the International Conference on Education Geneva: UNESCO, 2009

Floria L, Rouse M. (2009). The Inclusive Practice Project in Scotland: Teacher Education for Inclusive Education. Teaching and Teacher Education 2009; 25 (4): 594-601

European Agency for Development in Special Needs Education. (2010). Teacher Education for Inclusion- International Literature Review, Odense: European Agency for Development inSpecial Needs Education

Korthagen F, Loughran J, Russell T. (2006). Developing Fundamental Principles for Teacher Education Programs an Practices. Teaching and Teacher Education. 2006; 22 (8): 1020-1041

Bronack S, Riedl R, Tashner J. (2006). Learning in the Zone: A Social Constructivist Framework for Distance Education in 3Dimensional Virtual World. Interactive Learning. 2006; Vol.14,(3): 219-232

Alvesson M, Skoldberg K. (2009). Reflexive Methodology (2nd ed). London: Sage

Kershner R (2008). What do Teachers Need to Know about Meeting the Special Educational Needs an Disability. British Journal of Special Education. 2008; 33, (4): 168-172.

Casey C E, Childs R A. (2007). Teacher education programme admission criteria and what beginning teachers need to know to be successful. Canadian Journal of Educational Administration and Policy. 2007; 67: 1-24

Wormnæs S. (2008). Cross-cultural collaboration in special teacher education: An arena for facilitating reflection?. International Journal of Disability, Development and Education. 2008; 55(3): 205-225.

Boling E. (2007). 'Yeah', but I still don't want to deal with it'. Changes in Teacher Candidates Conceptions of Inclusion. Teaching Education. 2007; 18 (3): 217-231.

Jones, T G, Fuller M L. (2003). Teaching Hispanic Children. Boston: Allyn and Bacon

Blantilinger, E, Jimenez R, Klingner J, Pugach M, Richardson V. (2005). Qualitative studies in special needs education. Exceptional Children. 2005; 71(2): 195—207

Kvale, S (Ed.). (1996). Issues on Validity in Qualitative Research. Student literature, Lund, Sweden

Marshall, C, Rossman G B. (1994). Designing Qualitative Research. Thousand Oaks: Sage

Miles, M B, Huberman,A M. (1984). Qualitative Data Analysis: A Source Book of New Methods. London: Sage

Braun, V, Clarke V. (2006). Using thematic analysis in psychology. Qualitative Research in Psychology. 2006; 3(2): 77-101

Boeije, H. (2010). Analysis in Qualitative Research. London: Sage Publications

Deng, Z. (2004). Beyond training: Singaporean teacher preparation in the era of new educational initiatives. Teaching Education. 2004; 15(2): 159-173 